\title{
Inhibition by Propionyl-Coenzyme A of
}

\section{$N$-Acetylglutamate Synthetase in Rat Liver Mitochondria}

\author{
A POSSIBLE EXPLANATION FOR HYPERAMMONEMIA \\ IN PROPIONIC AND METHYLMALONIC ACIDEMIA
}

\author{
Francois X. Coude, Lawrence Sweetman, and William L. Nyhan, Department \\ of Pediatrics, University of California, San Diego, La Jolla, California 92093
}

\begin{abstract}
A B S TRACT In the search for the mechanism by which hyperammonemia complicates propionic and methylmalonic acidemia the effects of a series of acylcoenzyme A (CoA) derivatives were studied on the activity of $N$-acetylglutamate synthetase in rat liver mitochondria using acetyl-CoA as substrate. PropionylCoA was found to be a competitive inhibitor. The inhibition constant of $0.71 \mathrm{mM}$ is in the range of concentrations of propionate found in the serum of patients with propionic and methylmalonic acidemia. Propionyl$\mathrm{CoA}$ was also found to be a substrate for $\mathrm{N}$-acetylglutamate synthetase, forming $\mathrm{N}$-propionylglutamate. This compound was a weak activator of rat liver carbamoylphosphate synthetase; the activation constant was $1.1 \mathrm{mM}$ as compared with $0.12 \mathrm{mM}$ for $\mathrm{N}$ acetylglutamate. A decreased level of $N$-acetylglutamate in liver mitochondria that would follow inhibition of $\mathrm{N}$-acetylglutamate synthetase by propionyl-CoA would be expected to lead to hyperammonemia.

Methylmalonyl-CoA, tiglyl-CoA, and isovaleryl-CoA at a concentration of $3 \mathrm{mM}$ caused $30-70 \%$ inhibition of $\mathrm{N}$-acetylglutamate synthetase. The latter two compounds are readily detoxified by the formation of $\mathrm{N}$ acylglycine conjugates in liver, which may prevent large accumulations and could explain why hyperammonemia is not characteristic of patients with $\beta$ ketothiolase deficiency or isovaleric acidemia in whom these compounds would be expected to be elevated.
\end{abstract}

\section{INTRODUCTION}

Propionic and methylmalonic acidemia are inherited disorders of branched-chain amino acid metabolism in

Dr. Coude's present address is Departement de Génétique, Hôpital des Enfants Malades, 75730 Paris Cedex 15, France.

Received for publication 6 July 1979 and in revised form 7 August 1979. which there are specific deficiencies of the activity of propionyl-coenzyme A $(\mathrm{CoA})^{1}$ carboxylase and methylmalonyl-CoA mutase, respectively. These enzymes are in the pathway by which four amino acids, L-valine, L-isoleucine, L-methionine, and L-threonine are catabolized. Patients with these abnormalities present clinically with the ketotic hyperglycinemia syndrome with elevated concentrations of propionate in the blood (1-7). Two other disorders, isovaleric acidemia (8) and $\alpha$-methyl- $\beta$-hydroxybutyric aciduria (9) may also present with the ketotic hyperglycinemia syndrome. Involved patients have recurrent ketoacidosis, hyperglycinemia, neutropenia, thrombopenia, osteoporosis, and protein intolerance. This syndrome may be distinguished from a nonketotic hyperglycinemia (10).

Severe hyperammonemia has often been encountered in infants with propionic acidemia $(11,12)$ and methylmalonic acidemia $(13,14)$. A high degree of correlation has been obtained between the blood concentrations of ammonia and of propionate (15). Hyperammonemia has also been reported in one patient with $\alpha$-methyl- $\beta$-hydroxybutyric aciduria (9). Enzymes of the urea cycle have been studied in patients with propionic and methylmalonic acidemia and have generally been found to be normal $(11,14)$ although carbamoylphosphate synthetase activity has been observed to be low (15).

The pathway of mammalian urea biosynthesis, which serves for the removal of ammonia, is shown in Fig. 1. The synthesis of $\mathrm{N}$-acetylglutamate provides the natural allosteric activator of the ammonia-dependent mitochondrial carbamoylphosphate synthetase (16-18). N-Acetylglutamate synthetase is a mitochondrial enzyme activated by L-arginine $(19,20)$. Our

${ }^{1}$ Abbreviations used in this paper: CoA, coenzyme $\mathrm{A} ; \mathrm{V}_{\max }$, maximum velocity. 


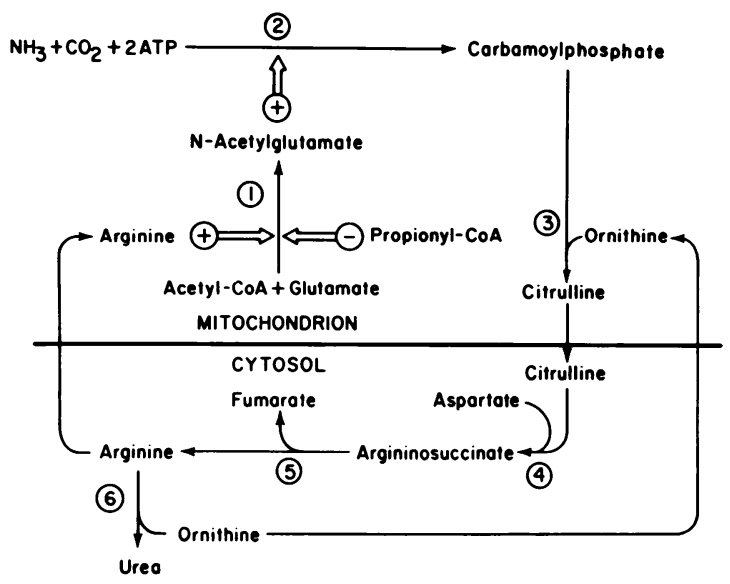

FIGURE 1 Enzymatic steps in the biosynthesis of urea: (1) $\mathrm{N}$-acetylglutamate synthetase; (2) carbamoylphosphate synthetase; (3) ornithine carbamoyl transferase; (4) argininosuccinate synthetase; (5) argininosuccinase; (6) arginase. $(+)$ indicates activation of $N$-acetylglutamate synthetase (1) by L-arginine and carbamoylphosphate synthetase (2) by $\mathrm{N}$-acetylglutamate, and (-) indicates inhibition of acetylglutamate synthetase (1) by propionyl-CoA.

hypothesis has been that the accumulation of propionyl-CoA in the liver mitochondria of patients with propionic and methylmalonic acidemia might lead to hyperammonemia through an inhibition of the biosynthesis of $\mathrm{N}$-acetylglutamate (21). It was the purpose of this study to assess the effects of propionyl-CoA and methylmalonyl-CoA on $\mathrm{N}$-acetylglutamate synthetase in rat liver mitochondria. It was found that propionyl-CoA was a significant inhibitor.

\section{METHODS}

Acetyl-CoA and propionyl-CoA were prepared by the method of Simon and Shemin (22). Tiglyl-CoA, isovaleryl-CoA, and methylmalonyl-CoA were purchased from the Sigma Chemical Co. (St. Louis, Mo.). N-Propionylglutamate was synthesized according to a modification of the method of Marshall et al. (23); $60 \mathrm{mmol}$ of glutamic acid suspended in $0.15 \mathrm{ml}$ of $\mathrm{H}_{2} \mathrm{O}$ were shaken at room temperature with $2 \mathrm{ml}$ of propionic anhydride and then with $2 \mathrm{ml}$ of water until only one phase was present; the solution was dried under nitrogen to remove propionic acid and anhydride; and then the residue was dissolved in water and adjusted to $\mathrm{pH} 6$ with $\mathrm{NaOH}$. A portion was analyzed by liquid-partition chromatography (24). $\left[1-{ }^{14} \mathrm{C}\right] \mathrm{L}$-glutamic acid was purchased from Amersham Corp. (Arlington Heights, Ill.) and purified by anion-exchange chromatography on Aminex-A 25 with $0.1 \mathrm{~N}$ acetic acid (25).

Wistar rats weighing $200-300 \mathrm{~g}$ were kept on a laboratory diet that contained $24 \%$ protein. They were killed by decapitation, and the livers were rapidly removed and kept at $4^{\circ} \mathrm{C}$ during the preparation of mitochondria according to the method of Myers and Slater (26). Mitochondria was suspended in $0.25 \mathrm{M}$ sucrose and subjected to sonic disintegration at 30 kcycles for $30 \mathrm{~s}$.

Measurement of N-acetylglutamate synthetase. N-Acetylglutamate synthetase was assayed by measuring the incor- poration of radioactivity from $\left[1-{ }^{14} \mathrm{C}\right] \mathrm{L}$-glutamic acid into $\mathrm{N}$ acetylglutamate. The standard assay system of $0.1 \mathrm{ml}$ contained these final concentrations: mitochondrial extract $(0.25$ $\mathrm{mg}$ of protein), $50 \mathrm{mM}$ Tris $\mathrm{HCl}, \mathrm{pH} 8.5,1 \mathrm{mM}\left[1-{ }^{14} \mathrm{C}\right] \mathrm{L}-$ glutamic acid $(2.25 \mathrm{mCi} / \mathrm{mM}), 4 \mathrm{mM}$ L-arginine, and acetylCoA and propionyl-CoA at different concentrations. After incubation for $15 \mathrm{~min}$ at $37^{\circ} \mathrm{C}$ the reaction was stopped by the addition of $0.025 \mathrm{ml}$ of $0.5 \mathrm{~N} \mathrm{H}_{2} \mathrm{SO}_{4}$. Acetyl-CoA was omitted in the blank. The reaction was linear for $20 \mathrm{~min}$ and gave a concave upward curve with increasing protein as reported by Tatibana and Shigesada (27). For the study of $\mathrm{N}$-propionylglutamate synthesis, the blank contained propionyl-CoA but not the mitochondrial extract, because $N$ propionylglutamate was formed nonenzymatically at high concentrations of propionyl-CoA.

Isolation of $\mathrm{N}$-acetyl- $\left[1-{ }^{14} \mathrm{C}\right]$ or $\mathrm{N}$-propionyl- $\left[1-{ }^{14} \mathrm{C}\right] \mathrm{L}$-glutamate. The labeled product was separated from free [1${ }^{14} \mathrm{C}$ ]glutamic acid with $0.9 \times 4-\mathrm{cm}$ cation exchange columns of BIORAD AG $50 \mathrm{~W}-\mathrm{X} 4, \mathrm{H}^{+}$form, 200-400 mesh (BioRad Laboratories, Richmond, Calif.). The acyl- $\left[{ }^{14} \mathrm{C}\right]$ glutamates were eluted with $6 \mathrm{ml}$ of water and were measured in routine assays by counting a portion in a liquid scintillation spectrometer. The unreacted $\left[1-{ }^{14} \mathrm{C}\right] \mathrm{L}$-glutamate was retained on the columns. A small amount of $\left[1-{ }^{14} \mathrm{C}\right] \alpha$-ketoglutarate formed and eluted with the acylglutamates and was corrected for by the blanks. $\mathrm{N}$-Acetylglutamate and $\mathrm{N}$-propionylglutamate were separated from each other and from $\alpha$-ketoglutarate by liquid-partition chromatography of a sample of the water eluate on silicic acid columns eluted with $30 \%$ t-amyl alcohol in chloroform. With gradient elution in this system $(24) \mathrm{N}$-acetyl-[1-14 C]L-glutamate coeluted with authentic standard at $R_{\mathrm{f}} 79.3$ relative to citrate at 100 , and $N$-propionyl-[ $\left[1{ }^{14} \mathrm{C}\right] \mathrm{L}$-glutamate coeluted with authentic $N$ propionylglutamate at $R_{\mathrm{f}} 61.5$.

Identity of the product of the reaction of acetyl-CoA and $\left[1-{ }^{14} \mathrm{C}\right] \mathrm{L}$-glutamate isolated by liquid-partition chromatography with $N$-acetylglutamate was confirmed by measuring its ability to activate rat liver carbamoylphosphate synthetase in an enzymatic assay (28), modified to increase the sensitivity to $2.5-40 \mathrm{nmol}$ of $\mathrm{N}$-acetylglutamate. The system contained the following in a final vol of $1 \mathrm{ml}$ : acetylglutamate extract, sonicated rat liver homogenate ( $2 \mathrm{mg}$ of protein), $5 \mathrm{mM}$ ATP, $20 \mathrm{mM} \mathrm{NH}_{4} \mathrm{Cl}, 15 \mathrm{M} \mathrm{MgCl}, 10 \mathrm{mM} \mathrm{KCl}, 20 \mathrm{mM}$ L-ornithine, $50 \mathrm{mM}$ Tris $\mathrm{HCl}(\mathrm{pH} 7.2)$, and $0.2 \mathrm{mM} \mathrm{NaH}{ }^{14} \mathrm{CO}_{3}(10 \mathrm{mCi} /$ $\mathrm{mM})$. Incubation was carried out at $37^{\circ} \mathrm{C}$ for $15 \mathrm{~min}$ and stopped by the addition of TCA to a final concentration of $5 \%$. The sample was dried overnight under a heat lamp to remove free ${ }^{14} \mathrm{CO}_{2}$, and its radioactivity was determined. The labeled product cochromatographed on ion-exchange column chromatography with authentic nonlabeled citrulline. The sensitivity of the assay was in the range of $2,500 \mathrm{dpm} /$ $\mathrm{nmol}$ of $\mathrm{N}$-acetylglutamate.

Measurement of carbamoylphosphate synthetase activity and its activation by $\mathrm{N}$-acetyl- and $\mathrm{N}$-propionylglutamate. The system contained the following in a final vol of $1 \mathrm{ml}$ : sonicated rat liver mitochondria $(5 \mathrm{mg}$ of protein), $5 \mathrm{mM}$ ATP, $20 \mathrm{mM} \mathrm{NH}_{4} \mathrm{Cl}, 15 \mathrm{mM} \mathrm{MgCl}, 10 \mathrm{mM} \mathrm{KCl}, 20 \mathrm{mM}$ L-ornithine, $50 \mathrm{mM}$ Tris $\mathrm{HCl}(\mathrm{pH} 7.2), 10 \mathrm{mM} \mathrm{NaH}{ }^{14} \mathrm{CO}_{3}$ $(0.2 \mathrm{mCi} / \mathrm{mM})$, and $N$-acetyl- or $N$-propionylglutamate at varying concentrations. Incubation was carried out at $37^{\circ} \mathrm{C}$ for 15 min and stopped by the addition of TCA to a final concentration of $5 \%$. The sample was dried overnight under a heat lamp to remove free ${ }^{14} \mathrm{CO}_{2}$, and its radioactivity was determined by liquid scintillation counting.

Protein was determined by a modification of the procedure of Lowry et al. (29). All kinetic data were calculated from double reciprocal plots weighted by $\mathrm{V}^{4}$ according to Wilkinson (30). Apparent $K_{\mathrm{m}}$ values for each sub- 
strate of $\mathrm{N}$-acetylglutamate synthetase were calculated as the mean of the $K_{m}$ values obtained at the various concentrations of the alternate substrate. The patterns of the kinetic plots and the apparent $K_{m}$ and $K_{i}$ values are not precise because of problems inherent in kinetic studies with crude enzyme preparations.

\section{RESULTS}

$\mathrm{N}$-Acetylglutamate synthetase in rat liver mitochondria was found to have an absolute requirement for $L$ arginine with an apparent activation constant $\left(\boldsymbol{K}_{\mathrm{a}}\right)$ of $1 \mathrm{mM}$ and, therefore, $4 \mathrm{mM}$ of $\mathrm{L}$-arginine was employed in all incubations. With acetyl-CoA and $\left[1-{ }^{14} \mathrm{C}\right] \mathrm{L}-$ glutamate as substrates the radioactive product was shown to be $N$-acetylglutamate by elution from a cation-exchange column with water, cochromatography with authentic $\mathrm{N}$-acetylglutamate on liquid-partition chromatography, and the ability of the product isolated by liquid-partition chromatography to activate rat liver carbamoylphosphate synthetase. The kinetic properties of $\mathrm{N}$-acetylglutamate synthetase are shown in Figs. 2A and B. The apparent mean $K_{m}$ for Lglutamate was $5.0 \mathrm{mM}$ and that for acetyl-CoA was $0.6 \mathrm{mM}$. The maximum velocity $\left(\mathrm{V}_{\max }\right)$ was $5.7 \mathrm{nmnol} /$ min per mg protein.

Propionyl-CoA was also a substrate for $\mathrm{N}$-acetylglutamate synthetase. The radioactive product formed when propionyl-CoA and $\left[1-{ }^{14} \mathrm{C}\right] \mathrm{L}-$ glutamate were used as substrates cochromatographed with authentic $\mathrm{N}$ propionylglutamate on liquid-partition chromatography. The kinetics of the synthetase in the presence of propionyl-CoA and L-glutamate are shown in Figs. $3 \mathrm{~A}$ and $\mathrm{B}$. The $K_{\mathrm{m}}$ for propionyl-CoA was $2.1 \mathrm{mM}$. This value was somewhat higher than the $K_{\mathrm{m}}$ for acetylCoA. The $K_{\mathrm{m}}$ for L-glutamate was $1.5 \mathrm{mM}$. The $V_{\max }$ was $0.23 \mathrm{nmol} / \mathrm{min}$ per $\mathrm{mg}$ protein when propionylCoA was used as substrate, which was only onetwenty-fifth of the $V_{\max }$ obtained with acetyl-CoA as substrate.

The synthesis of $\mathrm{N}$-acetylglutamate from acetylCoA was competitively inhibited by propionyl-CoA (Fig. 4A).

The replot of the slopes from the double reciprocal plot against the concentration of propionyl-CoA showed that the inhibition was hyperbolic (Fig. 4B). The replot of the reciprocal of the slopes in the presence of propionyl-CoA minus the slope in the absence of propionyl-CoA vs. the reciprocal of the concentration of propionyl-CoA is shown in Fig. 4B (31). This gives a straight line with a $K_{\mathrm{i}}$ of $0.71 \mathrm{mM}$ calculated from the negative reciprocal of the intercept on the abcissa (Fig. 4B). The $K_{\mathrm{i}}$ was somewhat lower than the $K_{m}$ for propionyl-CoA as a substrate. Other acyl CoA esters were tested as possible substrates or in-
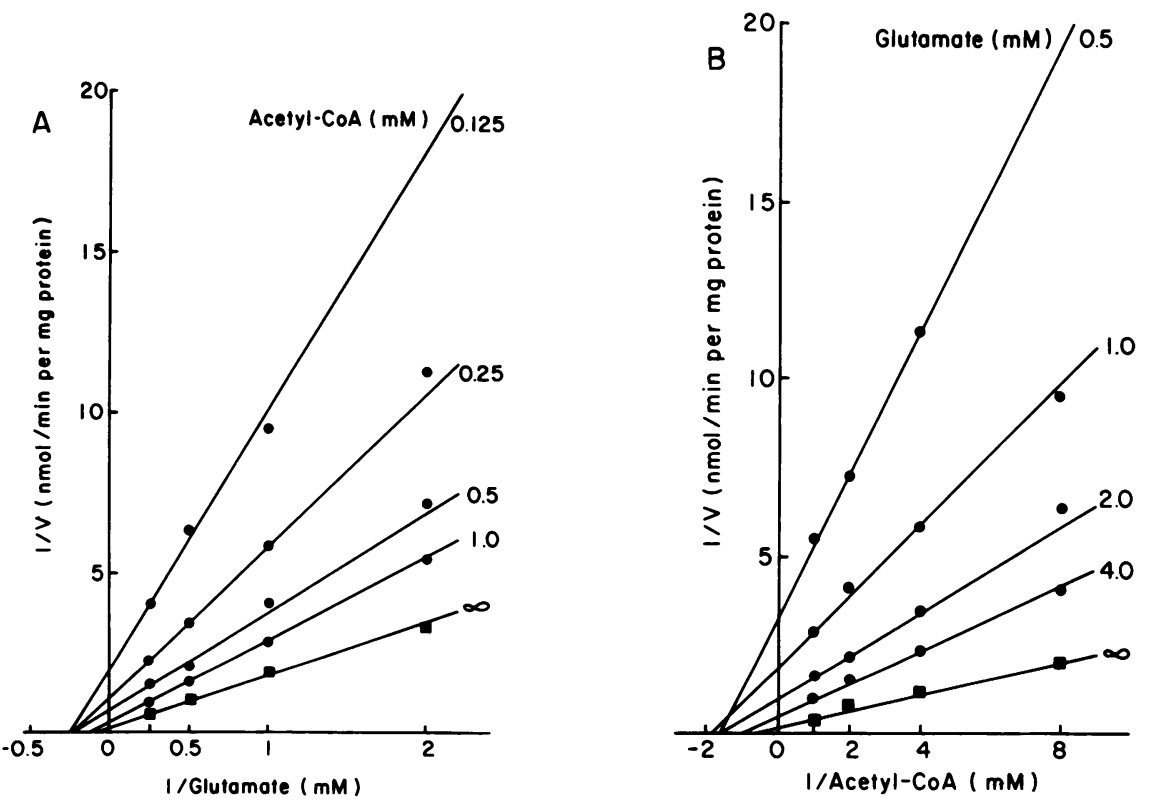

FIGURE 2 Kinetic properties of $N$-acetylglutamate synthetase. The substrates were acetyl-CoA and $\left[1-{ }^{14} \mathrm{C}\right] \mathrm{L}$-glutamate. (A) Kinetics for $\mathrm{L}$-glutamate: $\mathrm{N}$-acetyl-[1-14 $\left.\mathrm{C}\right]$ glutamate formation was measured in the presence of varying concentrations of L-glutamate and fixed concentrations of acetyl-CoA. For acetyl-CoA at infinite concentration, $1 / \mathrm{V}_{\max }-(\mathrm{V})$ from Fig. $2 \mathrm{~B}$ was plotted. Other conditions were as specified in Methods. (B) Kinetics for acetyl-CoA: $N$-acetyl-[1-14 $\mathrm{C}] N$-glutamate formation was measured in the presence of varying concentrations of acetyl-CoA and fixed concentrations of L-glutamate. For glutamate at infinite concentrations $1 / V_{\max }(\mathrm{V})$ from Fig. $2 \mathrm{~A}$ was plotted. 

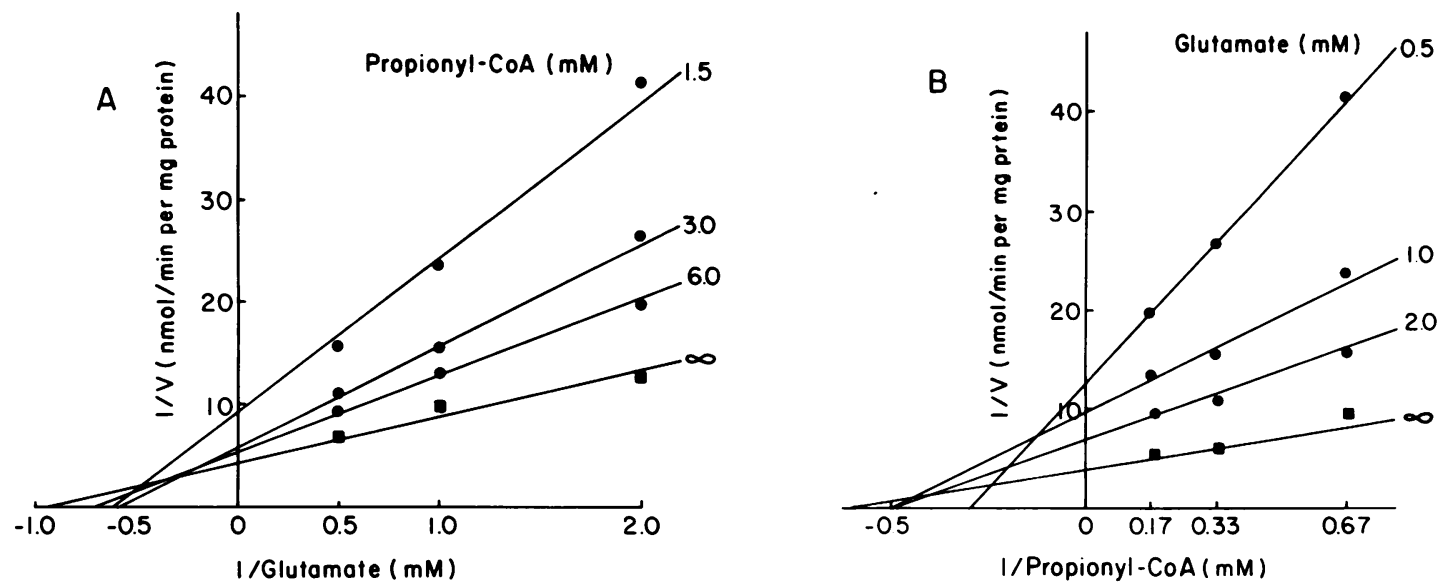

FIGURE 3 Kinetic properties of $N$-acetylglutamate synthetase in the presence of the substrates propionyl-CoA and $\left[1-{ }^{14} \mathrm{C}\right] \mathrm{L}$-glutamate. (A) Kinetics for L-glutamate: $\mathrm{N}$-propionyl-[1-14 $\left.\mathrm{C}\right]$ glutamate formation was measured in the presence of varying concentrations of L-glutamate and fixed concentrations of L-glutamate and fixed concentrations of propionyl-CoA. For propionyl-CoA at infinite concentration, $1 / \mathrm{V}_{\max }(\mathrm{V})$ from Fig. 3B was plotted. (B) Kinetics for propionyl-CoA: $\mathrm{N}$-propionyl-[1-14 $\mathrm{C}]$ glutamate formation was measured in the presence of varying concentrations of propionyl-CoA and fixed concentrations of L-glutamate. For glutamate at infinite concentrations, $1 / \mathrm{V}_{\max }$ from Fig. 3A was plotted.

hibitors of an $\mathrm{N}$-acetylglutamate synthetase (Table I). Methylmalonyl-CoA, isovaleryl-CoA, and tiglyl-CoA at concentrations of $3 \mathrm{mM}$ were not substrates. However, isovaleryl-CoA and tiglyl-CoA were inhibitors of the synthesis of $N$-acetylglutamate by 70 and $60 \%$, respectively, at concentrations of $3 \mathrm{mM}$ (Table II). Methylmalonyl-CoA was slightly inhibitory.
Because $N$-propionylglutamate was synthesized by $N$-acetylglutamate synthetase, the ability of $N$-propionylglutamate to serve as an activator of rat liver carbamoylphosphate synthetase was compared with that of $N$-acetylglutamate. $N$-Propionylglutamate was found to be an activator; the $K_{\mathrm{a}}$ was $1.1 \mathrm{mM}$ (Fig. 5B), which was ten times the $K_{\mathrm{a}}$ of $0.12 \mathrm{mM}$ for $N$ -
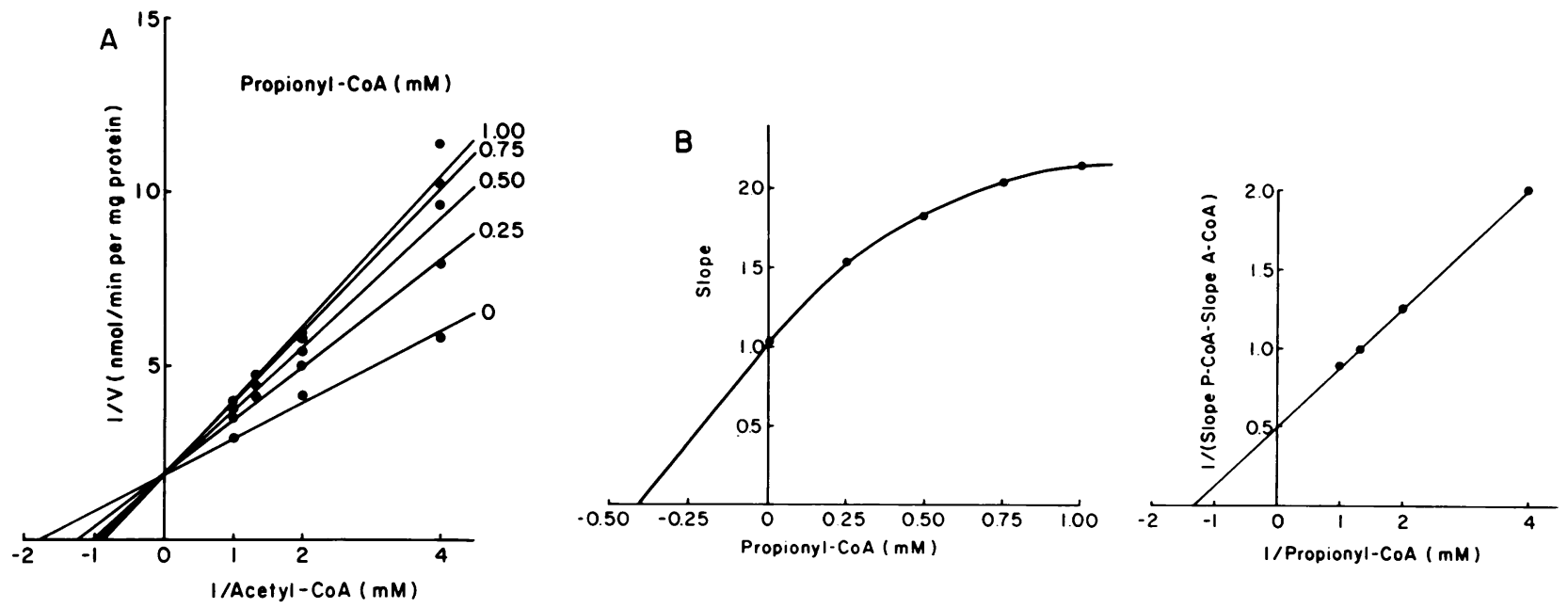

FIGURE 4 Inhibition of $N$-acetylglutamate synthetase by propionyl-CoA. (A) $N$-acetyl-[1- $\left.{ }^{14} \mathrm{C}\right]-$ glutamate synthesis was measured in the presence of varying concentrations of acetyl-CoA and fixed concentrations of propionyl-CoA. (B) The graph on the left shows the hyperbolic curve for the replot of the slopes from Fig. 4A vs. propionyl-CoA concentration. The graph on the right shows the straight line obtained when the reciprocal of the slope in the presence of propionyl-CoA minus the slope in the absence of propionyl-CoA was plotted against the reciprocal of the concentration of propionyl-CoA. 
TABLE I

Substrate Specificity of N-Acetylglutamate Synthetase

\begin{tabular}{llc}
\hline Labeled substrate & \multicolumn{1}{c}{ Acyl CoA thioester } & $\begin{array}{c}{\left[{ }^{14} \mathrm{C}\right] \mathrm{N}-} \\
\text { acylamino } \\
\text { acids formed }\end{array}$ \\
\hline & & nmol \\
{$\left[1-{ }^{14} \mathrm{C}\right] \mathrm{L}-$ glutamate } & $1 \mathrm{mM}$ Acetyl-CoA & $0.770^{*}$ \\
& $3 \mathrm{mM}$ Propionyl-CoA & $0.143^{*}$ \\
& $3 \mathrm{mM}$ Isovaleryl-CoA & 0.008 \\
& $3 \mathrm{mM}$ Methylmalonyl-CoA & 0.000 \\
& $3 \mathrm{mM}$ Tiglyl-CoA & 0.000 \\
\hline
\end{tabular}

Incubation conditions and separation of the products have been specified in Methods.

* The labeled acylamino acids formed cochromatographed respectively with authentic $N$-acetyl- and propionylglutamate on liquid-partition chromatography.

acetylglutamate (Fig. 5). The average $\mathrm{V}_{\max }$ with $\mathrm{N}$ propionylglutamate was $68 \%$ of that with $\mathrm{N}$-acetylglutamate, and significantly lower by Student's $t$ test $(P<0.005)$. Activation of carbamoylphosphate synthetase by $\mathrm{N}$-acetylglutamate and $\mathrm{N}$-propionylglutamate was approximately additive when both were present simultaneously (Figs. 5A and B).

\section{DISCUSSION}

$\mathrm{N}$-Acetylglutamate synthetase in rat liver mitochondria preparations was found to have a $K_{\mathrm{m}}$ of $0.6 \mathrm{mM}$ for acetyl-CoA and a $K_{\mathrm{m}}$ of $5.0 \mathrm{mM}$ for L-glutamate, which were similar to the $K_{\mathrm{m}}$ values of $0.7 \mathrm{mM}$ for acetyl$\mathrm{CoA}$ and $3.0 \mathrm{mM}$ for L-glutamate reported for the purified enzyme from rat liver $(20,32)$. PropionylCoA was shown to be a substrate with an affinity approximately three times less than that for acetyl-CoA. The $V_{\max }$ when propionyl-CoA was the substrate was one-twenty-fifth of the $V_{\max }$ for acetyl-CoA. Shigesada and Tatibana (19) reported that propionyl-CoA was a substrate for $\mathrm{N}$-acetylglutamate synthetase with an activity $6 \%$ of that with acetyl-CoA at $0.5 \mathrm{mM}$. We have shown that propionyl-CoA is a competitive inhibitor of $N$-acetylglutamate synthetase with a $k_{\mathbf{i}}$ value similar to its $K_{m}$ value.

These results suggest that elevated concentrations of propionyl-CoA in mitochondria of the liver of patients with propionic acidemia and methylmalonic acidemia may significantly inhibit the synthesis of $\mathrm{N}$ acetylglutamate. Evidence for elevated propionylCoA is provided by the fact that these patients have plasma propionate levels as high as $5-8 \mathrm{mM}(1,7)$ and excrete propionylglycine (33). The synthesis of propionylglycine in the liver is catalyzed by glycine$N$-acylase with a $K_{\mathrm{m}}$ for propionyl-CoA of $0.18 \mathrm{mM}$ for the bovine enzyme (34). In vitamin $B_{12}$-deficient rats, which provide a model for methylmalonic acidemia, levels of propionyl-CoA were elevated 15 -fold to 81.5 $\mathrm{nmol} / \mathrm{g}$ liver. This was similar to the levels of acetylCoA of $79.6 \mathrm{nmol} / \mathrm{g}$ and higher than those of methylmalonyl-CoA of $57 \mathrm{nmol} / \mathrm{g}$ (35). In isolated rat livers perfused with $10 \mathrm{mM}$ propionate, the concentrations of propionyl-CoA rose 10 -fold to $62.15 \mathrm{nmol} / \mathrm{g} \mathrm{(36)}$.

These data suggest that concentrations of propionylCoA may be elevated in the liver of patients with propionic acidemia and methylmalonic acidemia to levels higher than acetyl-CoA. Because the $K_{\mathrm{i}}$ for propionyl-CoA is similar to the $K_{m}$ for acetyl-CoA, significant inhibition of $\mathrm{N}$-acetylglutamate synthetase could result. A decreased level of $N$-acetylglutamate would decrease the activation of carbamoylphosphate synthetase and, hence, clearance of ammonia by the urea cycle (27). Some $N$-propionylglutamate may be synthesized in the liver of the patients but with an $\mathrm{K}_{\mathrm{a}}$ for carbamoylphosphate synthetase ten times higher than $\mathrm{N}$-acetylglutamate would not be expected to stimulate ureagenesis.

In vitro studies have suggested that a metabolite of propionate inhibits ureagenesis. Propionate did not directly inhibit carbamoylphosphate synthetase or ornithine transcarbamylase, but $5 \mathrm{mM}$ of propionate

TABLE II

Inhibition of N-Acetylglutamate Synthetase by CoA Esters of Organic Acid Catabolites of the Branched-Chain Amino Acids

\begin{tabular}{|c|c|c|c|}
\hline Labeled substrate & Acyl CoA thioester & $\begin{array}{l}N \text {-acetyl-[1-14 } \mathrm{C}] \text { glutamate } \\
\text { formed }\end{array}$ & $\begin{array}{c}\text { Percent } \\
\text { inhibition }\end{array}$ \\
\hline & & nmol & $\%$ \\
\hline$\left[1-{ }^{14} \mathrm{C}\right] \mathrm{L}$-glutamate & $\mathbf{0}$ & 0.770 & $\mathbf{0}$ \\
\hline \multirow[t]{4}{*}{$+1 \mathrm{mM}$ acetyl-CoA } & $3 \mathrm{mM}$ Propionyl-CoA & 0.204 & 73 \\
\hline & $3 \mathrm{mM}$ Isovaleryl-CoA & 0.229 & 70 \\
\hline & 3 mM Tiglyl-CoA & 0.310 & 60 \\
\hline & $3 \mathrm{mM}$ Methylmalonyl-CoA & 0.552 & 28 \\
\hline
\end{tabular}

The methodology was as in Table I. The radioactive product was cochromatographed with authentic $N$-acetylglutamate on liquid-partition chromatography. 

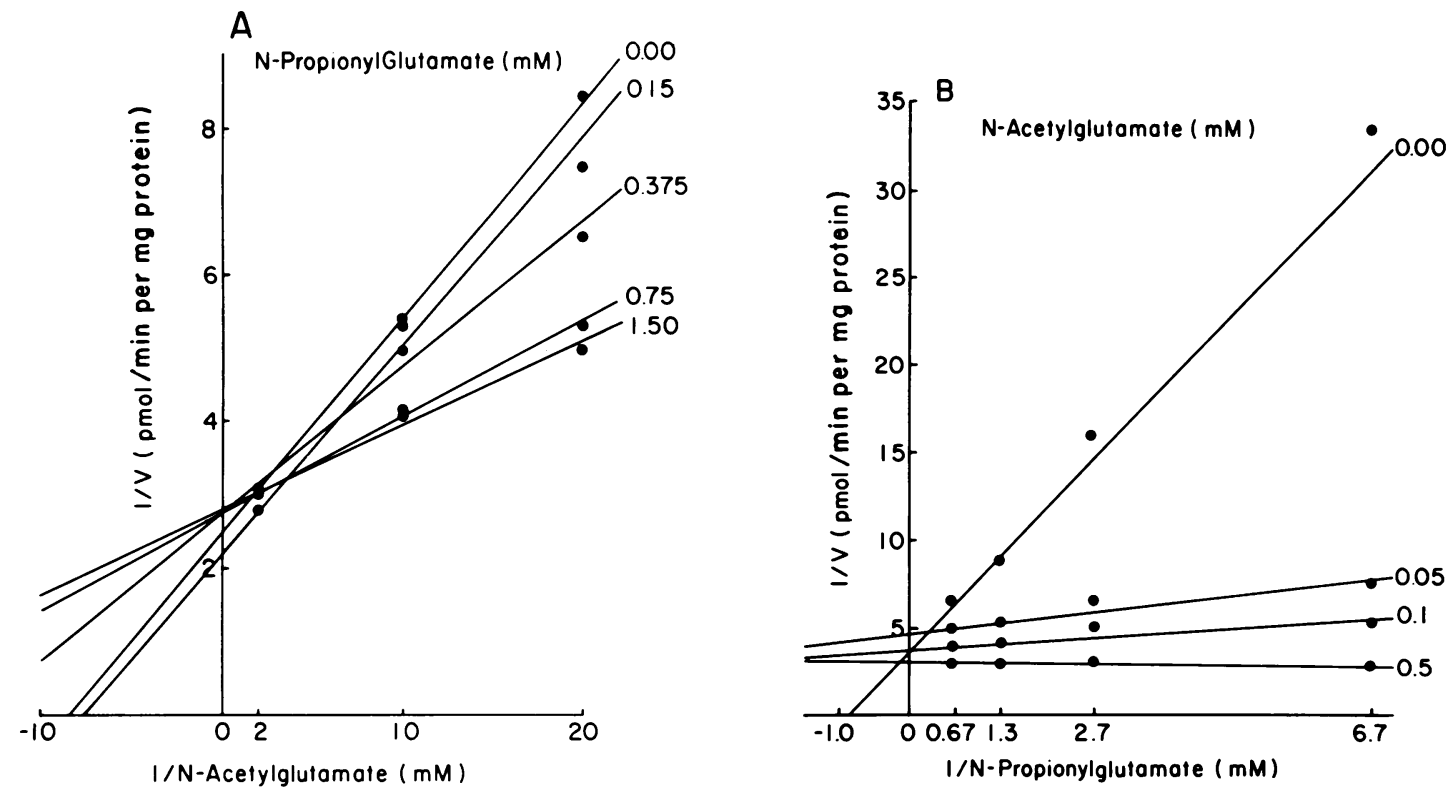

FIGURE 5 Activation of carbamoylphosphate synthetase by $N$-acetylglutamate and $N$-propionylglutamate. The formation of $\left[{ }^{14} \mathrm{C}\right]$ citrulline from $\mathrm{NaH}^{14} \mathrm{CO}_{3}$ was determined at various concentrations of $\mathrm{N}$-acetylglutamate and $\mathrm{N}$-propionylglutamate as described in Methods.

inhibited ureagenesis from ammonia and ornithine by $40 \%$ in rat liver slices (37). Propionate also inhibited the synthesis of citrulline in isolated rat liver mitochondria (38). It was reported in a recent abstract that propionyl-CoA, and to a lesser extent tiglyl-CoA and methylmalonyl-CoA, produced time- and concentration-dependent inhibition of carbamoylphosphate synthetase activity in homogenates of human and rat liver (39). This was apparently a result of a direct inhibition of carbamoylphosphate synthetase and not of inhibition of $\mathrm{N}$-acetylglutamate synthetase because $10 \mathrm{mM}$ of $\mathrm{N}$-acetylglutamate was added as an activator. Thus, there may be more than one site for inhibition of ureagenesis by propionyl-CoA.

In our study, methylmalonyl-CoA was only slightly inhibitory of $\mathrm{N}$-acetylglutamate synthetase activity, and, therefore, the hyperammonemia in methylmalonic acidemia is probably caused by increased levels of propionyl-CoA. Isovaleryl-CoA and tiglyl-CoA at high concentrations were shown to inhibit $N$-acetylglutamate synthetase almost as much as did propionyl-CoA. The fact that hyperammonemia has not been described in patients with isovaleric acidemia and in only one patient with $\beta$-ketothiolase deficiency (9) may be explained by the finding that isovaleryl-CoA and tiglyl-CoA are more rapidly metabolized by glycine $\mathrm{N}$-acylase than propionyl-CoA (34). Large amounts of isovalerylglycine are excreted by patients with isovaleric acidemia (40) and tiglylglycine by patients with $\beta$-ketothiolase deficiency (9), whereas only small amounts of propionylglycine and tiglylglycine are excreted by patients with propionic acidemia $(31,41)$.
It may be possible to prevent acute episodes of hyperammonemia in patients with propionic and methylmalonic acidemia by administering an activator of carbamoylphosphate synthetase to compensate for decreased levels of $\mathrm{N}$-acetylglutamate. Analogues of $\mathrm{N}$-acetylglutamate such as $N$-carbamoyl-L-glutamate have been shown to activate carbamoylphosphate synthetase (42). Kim et al. (43) demonstrated that $N$ acetylglutamate given intraperitoneally was ineffective in protecting against lethal doses of ammonium acetate in rats but that $\mathrm{N}$-carbamoylglutamate along with L-arginine was effective. $\mathrm{N}$-carbamoylglutamate might provide effective therapy in patients with propionic and methylmalonic acidemia when acute episodes of hyperammonemia first occur.

\section{ACKNOWLEDGMENTS}

This study was supported in part by U. S. Public Health Service grant HDO4608 from the National Institute of Child Health and Human Development, National Institutes of Health, Bethesda, Md. and the Délégation Générale à la Recherche Scientifique et Technique, Paris, France (grant BRD P578).

\section{REFERENCES}

1. Hommes, F. A., J. R. G. Kuipers, J. D. Elema, J. F. Jansen, and J. H. P. Jonxis. 1968. Propionic acidemia, a new inborn error of metabolism. Pediatr. Res. 2: 519-524.

2. Hsia, Y. E., K. J. Scully, and L. E. Rosenberg. 1969. Defective propionate carboxylation in ketotic hyperglycinemia. Lancet. I: 757-758. 
3. Ando, T., K. Rasmussen, W. L. Nyhan, G. N. Donnell, and N. D. Barnes. 1971. Propionic acidemia in patients with ketotic hyperglycinemia. J. Pediatr. 78: 827-832.

4. Ando, T., W. L. Nyhan, J. D. Connor, K. Rasmussen, G. Donnell, N. Barnes, D. Cottom, and D. Hull. 1972. The oxidation of glycine and propionic acid in propionic acidemia with ketotic hyperglycinemia. Pediatr. Res. 6: 576-583.

5. Rosenberg, L. E., A. C. Lilljeqvist, and Y. E. Hsia. 1968. Methylmalonic aciduria: an inborn error leading to metabolic acidosis, long-chain ketonuria and intermittent hyperglycinemia. New Engl. J. Med. 278: 1319-1322.

6. Boisse, J., R. Perelman, J. C. Rudler, C. Charpentier, and J. P. Pousset. 1971. L'acidémie méthylmalonique, une cause nouvelle d'acidocétose grave. Sem. Hop. Paris. 47: 53-65.

7. Van den Berg, H., M. Th. E. Boelkens, and F. A. Hommes. 1976. A case of methylmalonic and propionic acidemia due to methylmalonyl-CoA carbonylmutase apoenzyme deficiency. Acta Paediatr. Scand. 65: 113-118.

8. Ando, T., W. G. Klingberg, A. N. Ward, K. Rasmussen, and W. L. Nyhan. 1971. Isovaleric acidemia presenting with altered metabolism of glycine. Pediatr. Res. 5: 478-486.

9. Hillman, R. E., and J. P. Keating. 1974. Beta-ketothiolase deficiency as a cause of the "ketotic hyperglycinemia syndrome." Pediatrics. 53: 221-225.

10. Gerritsen, T., E. Kaveggia, and H. A. Waisman. 1965. A new type of idiopathic hyperglycinemia with hypoxaluria. Pediatrics. 36: 882-891.

11. Landes, R. D., G. B. Avery, F. A. Walker, and Y. E. Hsia. 1972. Propionyl CoA carboxylase deficiency (propionic acidemia): another cause of hyperammonemia. Pediatr. Res. 6: 394.

12. Shafai, T., L. Sweetman, W. Weyler, S. I. Goodman, P. V. Fennessey, and W. L. Nyhan. 1978. Propionic acidemia with severe hyperammonemia and defective glycine metabolism. J. Pediatr. 92: 84-86.

13. Morrow, G., L. A. Barness, V. H. Auerbach, A. M. Digeorge, T. Ando, and W. L. Nyhan. 1969. Observations on the coexistence of methylmalonic acidemia and glycinemia. J. Pediatr. 74: 680-690.

14. Packman, S., M. J. Mahoney, K. Tanaka, and Y. E. Hsia. 1978. Severe hyperammonemia in a newborn infant with methylmalonyl-CoA mutase deficiency. J. Pediatr. 92: $769-771$.

15. Wolf, B., Y. E. Hsia, K. Tanaka, and L. E. Rosenberg. 1978. Correlations between serum propionate and blood ammonia concentrations in propionic acidemia.J. Pediatr. 93: $471-473$.

16. Hall, L. M., R. L. Metzenberg, and P. P. Cohen. 1958. Isolation and characterization of a naturally occurring cofactor of carbamyl phosphate biosynthesis. J. Biol. Chem. 230: 1013-1021.

17. Shigesada, K., K. Aoyagi, and M. Tatibana. 1978. Role of acetyl glutamate in ureotelism. Variations in acetyl glutamate level and its possible significance in control of urea synthesis in mammalian liver. Eur. J. Biochem. 85: 385-391.

18. Shigesada, K., and M. Tatibana. 1971. Role of acetylglutamate in ureotelism. I. Occurrence and biosynthesis of acetylglutamate in mouse and rat tissues. J. Biol. Chem. 246: 5588-5595.

19. Shigesada, K., and M. Tatibana. 1971. Enzymatic synthesis of acetylglutamate by mammalian liver preparations and its stimulation by arginine. Biochem. Biophys. Res. Commun. 44: 1117-1124.

20. Shigesada, K., and M. Tatibana. 1978. N-Acetylglutamate synthetase from rat liver mitochondria: partial purification and catalytic properties. Eur. J. Biochem. 84: 285-291.

21. Bachmann, C. 1974. Urea cycle. In Heritable Disorders of Amino Acid Metabolism. W. L. Nyhan, editor. John Wiley \& Sons, Inc., New York. 361-386.

22. Simon, E. J., and D. Shemin. 1953. The preparation of S-succinyl-Coenzyme A.J. Am. Chem. Soc. 75: 2520.

23. Marshall, M., R. L. Metzenberg, and P. P. Cohen. 1961. Physical and kinetic properties of carbamyl phosphate synthetase from frog liver. J. Biol. Chem. 236: 22292237.

24. Sweetman, L. 1974. Liquid partition chromatography and gas chromatography-mass spectrometry in identification of acid metabolites of amino acids. In Heritable Disorders of Amino Acid Metabolism. W. L. Nyhan, editor. John Wiley \& Sons, Inc., New York. 730-751.

25. Hirs, C. H. W., S. Moore, and W. H. Stein. 1954. The chromatography of aminoacids on ion exchange resins. Use of volatile acids for elution. J. Am. Chem. Soc. 76: 6063-6065.

26. Myers, D. K., and E. C. Slater. 1957. The enzyme hydrolysis of adenosine triphosphate by liver mitochondria. I. Activities at different $\mathrm{pH}$ values. Biochem. J. 67: $558-571$.

27. Tatibana, M., and K. Shigesada. 1976. Regulation of urea biosynthesis by the acetylglutamate-arginine system. In The Urea Cycle. S. Grisolia, R. Baguena, and F. Mayors, editors. John Wiley \& Sons, Inc., New York. 301-313.

28. McGivan. J. D., N. M. Bradford, and J. Mendes-Mourao. 1976. The regulation of carbamoyl phosphate synthetase activity in rat liver mitochondria. Biochem. J. 154: 415-421.

29. Lowry, O. H., N. J. Roseborough, A. L. Farr, and R. J. Randall. 1951. Protein measurement with the Folin phenol reagent. J. Biol. Chem. 193: 265-275.

30. Wilkinson, G. N. 1961. Statistical estimations in enzyme kinetic's. Biochem. J. 80: 324-332.

31. Cleland, W. W. 1963. The kinetic's of enzyme-catalyzed reactions with two or more substrates or products. II. Inhibition: nomenclature and theory. Biochim. Biophys. Acta. 67: 173-187.

32. Tatibana, M., K. Shigesada, and M. Mori. 1976. Acetylglutamate synthetase. In The Urea Cycle. S. Grisolia, R. Baguena, and F. Mayors, editors. John Wiley \& Sons, Inc., New York. 95-105.

33. Rasmussen, K., T. Ando, W. L. Nyhan, D. Hull, D. Cottom, G. Donnell, K. Wadlington, and A. W. Kilroy. 1972. Excretion of propionylglycine in propionic acidemia. Clin. Sci. (Oxf.). 42: 665-671.

34. Bartlett, K., and D. Gompertz. 1974. The specificity of glycine- $N$-acylase and acylglycine excretion in the organicuacidaemias. Biochem. Med. 10: 15-23.

35. Frenkel, E. P., R. L. Kitchens, L. B. Hersh, and R. Frenkel. 1974. Effects of vitamin B12 deprivation on the in vivo levels of Coenzyme A intermediates associated with propionic metabolism. J. Biol. Chem. 249: 6984-6991.

36. Söling, H. D., and B. Volkmann. 1973. A sensitive assay for the determination of propionyl-CoA in biological material. Anal. Biochem. 52: 305-310.

37. Glasgow, A. M., and H. P. Chase. 1976. Effect of propionic acid on fatty acid oxidation and ureagenesis. Pediatr. Res. 10: 683-686.

38. Glasgow, A. M., and H. P. Chase. 1976. Effect of pent4-enoic acid, propionic acid and other short-chain fatty acids on citrulline synthesis in rat liver mitochondria. Biochem. J. 156: 301-307. 
39. Gruskay, J. A., and L. E. Rosenberg. 1979. Inhibition of hepatic mitochondrial carbamylphosphate synthetase (CPSI) by acyl CoA esters: possible mechanism of hyperammonemia in the organic acidemias. Pediatr. Res. 13: 475. (Abstr.)

40. Tanaka, K., and K. J. Isselbacher. 1967. The isolation and identification of $\mathrm{N}$-isovalerylglycine from urine of patients with isovaleric acidemia. J. Biol. Chem. 242: 2966-2972.

41. Rasmussen, K., T. Ando, W. L. Nyhan, D. Hull, D. Cottom,
S. W. Kilroy, and W. Wadlington. 1972. Excretion of tiglylglycine in propionic acidemia. J. Pediatr. 81: 970-972.

42. Grisolia, S., and P. P. Cohen. 1953. Catalytic role of glutamate derivatives in citrulline biosynthesis. J. Biol. Chem. 204: 753-757.

43. Kim, S., W. K. Paik, and P. P. Cohen. 1972. Ammonia intoxication in rats: protection by $\mathrm{N}$-carbamoyl-L-glutamate plus L-arginine. Proc. Natl. Acad. Sci. U. S. A. 69: 3530-3533. 